\title{
Analisis Tata Kelola Aplikasi Presensi Karyawan (COBIT 4.1 Domain Monitoring and Evaluate)
}

\author{
Elia Juniarti Simbolon*1, Hanna Prillysca Chernovita ${ }^{2}$, Melkior N.N. Sitokdana ${ }^{3}$ \\ ${ }^{1,2,3}$ Universitas Kristen Satya Wacana; Jl. Diponegoro No. 52-60, Salatiga, Kec. Sidorejo, \\ Kota Salatiga, Jawa Tengah 50711,(0298) 321212 \\ ${ }^{3}$ Jurusan Sistem Informasi, FTI UKSW, Salatiga \\ e-mail: *11 eliajuniartisimbolon@gmail.com, ${ }^{2}$ hanna.chernovita@uksw.edu, \\ ${ }^{3}$ melkior.sitokdana@uksw.edu
}

\begin{abstract}
Abstrak
Unit Pelayanan Pendapatan Daerah (UPPD) Kota Salatiga adalah Instansi pemerintah, bertugas dalam penerimaan pendapatan daerah melalui pengoordinasian dan pemungutan pajak, retribusi, bagi hasil pajak, dan lainya. Peninjauan kelayakan sistem informasi merupakan cara melindungi data dari penyalahgunaan informasi. Karena itu diperlukan pengukuran proses pada aplikasi pendukung kerja, untuk mengukur kelayakan serta mencapai tujuan bisnis instansi. Penelitian menggunakan Kerangka kerja COBIT 4.1 melalui Domain Monitoring and Evaluate (ME), kemudian tingkat kematangan melalui maturity level dan GAP. Dalam domain ME pada COBIT 4.1 terdapat 4 kontrol yakni, ME1 (Monitor and Evaluate IT Performance), ME2 (Monitor and Evaluate Internal Control), ME3 (Obtain Independent Assurance), dan ME4 (Provide IT Governance). Penelitian difokuskan pada proses manajemen, pengelolaan pengendalian internal serta berjalan atau tidak suatu peraturan. Hasil penelitian didapatkan melalui observasi, wawancara dan kuesioner. Pada hasil implementasi, framework ME pada tingkat Defined Process, diketahui maturity level memiliki rata-rata 3,8 dengan expected level tingkat 4 yaitu managed and measurable, serta memiliki nilai GAP sebesar 0,2. Hasil maturity level, subdomain nilai tertinggi pada ME4 yakni 3,92 yang berada pada level Defined Process dan sudomain nilai terendah pada ME1 dengan nilai 3,59 yang berada pada level Defined Process. Diharapkan penelitian ini dapat menjadi tolak ukur untuk kemajuan instansi kedepannya.
\end{abstract}

Kata kunci-COBIT 4.1, Domain Monitoring and Evaluate, Maturity Level dan GAP, UPPD Kota Salatiga

\section{Abstract}

The Regional Revenue Service Unit (UPPD) of Salatiga City is a government agency, responsible for the receipt of regional revenues through the coordination and collection of taxes, levies, tax revenue sharing, and others. Information system feasibility review is a way to protect data from misuse of information. Therefore, it is necessary to measure the process on the work support application, to measure the feasibility and achieve the business objectives of the agency. The research used cobit framework 4.1 through Domain Monitoring and Evaluate (ME), then maturity level through maturity level and GAP. In the domain ME on COBIT 4.1 there are 4 controls namely, ME1 (Monitor and Evaluate IT Performance), ME2 ( Monitor and Evaluate InternalControl), ME3 (ObtainIndependent Assurance), and ME4 ( ProvideIT Governance). Research is focused on the management process, internal control management as well as running or not a regulation. The results were obtained through observations, interviews and questionnaires. In the implementation result, me 
framework at defined processlevel, known maturity level has an average of 3.8 with expected level level 4 which is managed and measurable, andhas a GAP value of 0.2. Maturity level result, the highest value subdomain on ME4 is 3.92 which is at defined process level and sudomain lowest value on ME1 with 3.59 value which is at Defined Processlevel. It is expected that this research can be a benchmark for the progress of the agency in the future.

Keywords-COBIT 4.1, Domain Monitoring and Evaluate, Maturity Level and GAP, UPPD Salatiga City

\section{PENDAHULUAN}

Teknologi Informasi (TI) merupakan salah satu sarana pengolahan data yang sudah banyak diterapkan dan sudah menjadi kebutuhan bagi suatu perusahaan atau instansi. Dikarenakan banyak keuntungan dan manfaat yang dirasakan dalam proses pengelolaannya untuk mendukung pekerjaan menjadi efektif dan efisien. Penerapan teknologi dalam berbagai jenis pengelolaan data sudah merupakan hal yang wajib dilakukan, dikarenakan Unit Pelayanan Pendapatan Daerah (UPPD) Kota Salatiga adalah Kota daerah yang selanjutnya akan mengirim data ke pusat Provinsi di Unit Pelayanan Pendapatan Daerah (UPPD) Kota Semarang. Peninjauan kelayakan sistem informasi pada aplikasi - aplikasi pengolahan data institusi merupakan salah satu cara untuk melindungi data dari penyalahgunaan informasi, demi menyediakan informasi yang mendukung sasaran dan kebutuhan bisnis institusi, maka penggunaan sumber daya teknologi informasi perlu diperhatikan dan diatur prosesnya.

Data informasi bisnis institusi yang terdapat dalam berbagai aplikasi maupun sistem informasi yang dikelola oleh Unit Pelayanan Pendapatan Daerah (UPPD) Kota Salatiga, merupakan suatu informasi yang harus terjamin keamanan data informasinya karena maraknya serangan pencurian data, sabotase, dan risiko keamanan data lainnya yang merupakan suatu masalah yang sangat besar konsekuensinya. Karena itu diperlukan suatu pengukuran proses tingkat kematangan atau Maturity Level pada aplikasi pendukung kerja E-Presensi yang digunakan oleh karyawan untuk mengukur kelayakan serta untuk mencapai suatu kendali tertentu sesuai tujuan bisnis instansi. Penelitian ini menggunakan Kerangka kerja COBIT 4.1 dengan menerapkan Domain Monitoring and Evaluate (ME) yang kemudian akan ditentukan dan dibahas tingkat kematangan prosesnya melalui maturity level dan GAP. Sehingga didapatkan hasil serta rekomendasi yang dapat dijadikan acuan untuk melihat proses berbagai sistem khususnya aplikasi E-presensi yang sudah diteliti kelayakannya, demi kelancaran proses bisnis untuk mencapai visi dan misi dari institusi Unit Pelayanan Pendapatan Daerah (UPPD) Kota Salatiga.

\section{METODE PENELITIAN}

\subsection{Kajian Pustaka}

2. 1.1 Tata Kelola Teknologi Informasi

"Pemanfaatan teknologi informasi dalam proses pemerintahan dapat meningkatkan efisiensi, efektivitas, transparansi, dan akuntabilitas penyelenggaraan pemerintahan. Agar implementasi tata kelola TI berjalan dengan efektif dan efisien. [1]". Suatu organisasi membutuhkan adanya pengelolaan yang baik, demi menghasilkan tujuan dari organisasi tersebut, pengelolaan yang baik perlu didukung dengan memaksimalkan sumber daya yang ada, pada saat ini teknologi sudah akrab dengan proses bisnis. Segala bagian dalam proses bisnis 
sudah hampir diselaraskan dengan penggunaan Teknologi di dalamnya, melihat dari hal tersebut perlunya pengelolaan tata kelola teknologi informasi yang baik sudah selayaknya diterapkan, mulai dari perencanaan, pelaksanaan, implementasi juga monitoring. Pengukuran uji kelayakan suatu proses bisnis saat ini juga sudah banyak diterapkan oleh banyak instansi baik perusahaan maupun organisasi.

\section{1.2 Absensi}

"Presensi adalah sebuah kegiatan pengambilan data guna mengetahui jumlah kehadiran pada suatu acara. Setiap kegiatan yang membutuhkan informasi mengenai peserta tentu akan melakukan presensi [2]". Data dari absensi kehadiran biasanya disimpan untuk digunakan oleh pihak yang berkepentingan [3], penggunaannya secara umum dibedakan menjadi dua yaitu:

1. Absensi manual, yang merupakan cara penulisan kehadiran dengan menggunakan pena berupa tanda tangan.

2. Absensi non manual, yang merupakan cara penulisan kehadiran dengan menggunakan alat yang terkomputerisasi, bisa menggunakan kartu RFID ataupun fingerprint.

\section{1.3 Manajemen Resiko}

Pemahaman pengelolaan risiko yang baik akan bermanfaat bagi pemulihan maupun analisa pencegahan munculnya risiko yang mungkin terjadi, sehingga suatu instansi perusahaan atau organisasi sudah menyiapkan perencanaan antisipasi terhadap suatu masalah risiko pada masa mendatang. Ada beberapa proses manajemen risiko [4] terhadap suatu kebijakan yang terdiri dari:

a. Identifikasi Risiko

Perusahaan harus mengidentifikasikan serta mengelompokkan deviasi atau penyimpangan sebagai akibat tidak terealisasinya pelaksanaan strategi usaha maupun rencana bisnis yang telah ditetapkan, terutama yang berdampak signifikan terhadap permodalan perusahaan.

b. Pengukuran Risiko

Perusahaan melakukan pengukuran risiko dengan cara: mengidentifikasi perubahan lingkungan bisnis yang berdampak negatif terhadap asumsi awal dari rencana strategis dan mengukur dampak negatif suatu peristiwa terhadap kinerja bisnis perusahaan, baik secara keuangan maupun non keuangan. Apabila tingkat risiko lebih tinggi dibandingkan kemampuan perusahaan dalam menyerap resik, maka akan dikembangkan suatu strategi untuk mengurangi atau memitigasi risiko tersebut.

c. Pemantauan Risiko

Perusahaan wajib memantau pengembangan implementasi strategi secara berkala. Pemantauan dilakukan dengan memperhatikan pengalaman kerugian di masa lalu. Isu - isu strategis akibat perubahan wajib dilaporkan kepada jajaran direksi disertai dengan analisis dampak dan tindakan perbaikan yang diperlukan.

d. Pengendalian Risiko

Perusahaan harus memiliki sistem pengendalian dengan cara membandingkan hasil aktual dengan hasil yang diharapkan. Pengendalian risiko terhadap kinerja keuangan dapat dilakukan dengan menyusun cash flow budgeting yang nantinya akan dibandingkan dengan pencapaian perusahaan, di mana akan memunculkan suatu rencana strategis untuk memitigasi risiko.

\section{1.4 COBIT 4.1}

Dalam sebuah proses bisnis diperlukan adanya kerangka kerja, untuk dapat membantu berbagai pihak untuk menangani celah antara masalah teknis, kebutuhan kontrol dan risiko bisnis. Untuk mencapai tujuan bisnis, informasi dibutuhkan untuk sesuai dengan kriteria kendali

Elia Juniarti Simbolon, et., al [Analisis Tata Kelola Aplikasi Presensi Karyawan (COBIT 4.1 Domain Monitoring and Evaluate) 
tertentu, dimana COBIT 4.1 mengacu hal tersebut sebagai kebutuhan bisnis dan informasi [5]. Keterkaitan antar Domain dapat dijelaskan sebagai berikut [6]:

a. Plan and Organise (PO)

Domain ini mencangkup strategi dalam mengidentifikasi bagaimana TI secara maksimal dapat berkontribusi dalam mencapai tujuan organisasi.

b. Acquisition and Implementation (AI)

Domain ini membantu dalam merealisasikan strategi dan solusi TI yang telah diimplementasikan dan terintegrasi ke dalam proses bisnis.

c. Delivery and Support (DS)

Domain ini memberikan fokus utama pada aspek penyampaian dari kebutuhan layanan TI. Mencangkup pemberian layanan, pengelolaan keamanan dan komunitas, dukungan layanan bagi pengguna, fasilitas operasional, serta proses dukungan yang memungkinkan pengoperasian sistem TI tersebut dengan efektif dan efisien.

d. Monitoring and Evaluate (ME)

Domain ini membahas setiap proses TI yang harus dinilai secara teratur dalam setiap waktu untuk menjaga kualitas dan pemenuhan syarat pengendalian.

Selain Domain yang digunakan dalam COBIT 4.1, ada juga Maturity Level yang digunakan untuk penentuan tingkat kematangan proses TI. Didalamnya akan membahas beberapa kriteria untuk suatu level kematangan yang hasilnya didapat dari pengukuran menggunakan domain COBIT 4.1. Terdapat enam kriteria maturity level seperti dijelaskan pada tabel 1.

Tabel 1. Maturity Level

\begin{tabular}{c|c}
\hline LEVEL & Kategori \\
$\mathbf{0}$ & Non Existent \\
$\mathbf{1}$ & Initial \\
$\mathbf{2}$ & Repeatable \\
$\mathbf{3}$ & Defined \\
$\mathbf{4}$ & Managed \\
$\mathbf{5}$ & Optimised \\
\hline
\end{tabular}

Matriks untuk menunjukkan peran dan tanggung jawab tugas, atau yang disebut dengan RACI adalah matriks yang menjelaskan peran berbagai pihak yang ada untuk menyelesaikan pekerjaan dalam suatu proyek atau proses bisnis. RACI merupakan singkatan dari empat peran yaitu Responsible, Accountable, Consulted dan Informed (ITGI, 2007). Diagram RACI diterapkan di setiap aktivitas yang dijalankan pada pengendalian objektif TI [6].

\subsection{Metode Penelitian}

Alur tahapan yang akan digunakan untuk penyelesaian penelitian terdapat pada gambar 1 . adalah Metode Campuran, dimana data penelitian yang dihasilkan didapatkan melalui cara penelitian Kuantitatif dan kualitatif. Data kuantitatif merupakan data yang hasilnya dapat dihitung dan diukur untuk mendapatkan hasil kesimpulannya, pada penelitian ini data kualitatif dengan cara memberika kuesioner pada karyawan pengguna dan admin yang memiliki hak - hak tertentu pada sistem. Lain dari itu juga ada data kualitatif, merupakan data yang hasil kesimpulannya didapat melalui observasi, angket, dan wawancara, pada penelitian ini data kuantitatif dipeoleh dengan observasi lingkungan kerja serta wawancara beberapa karyawan terkait. 


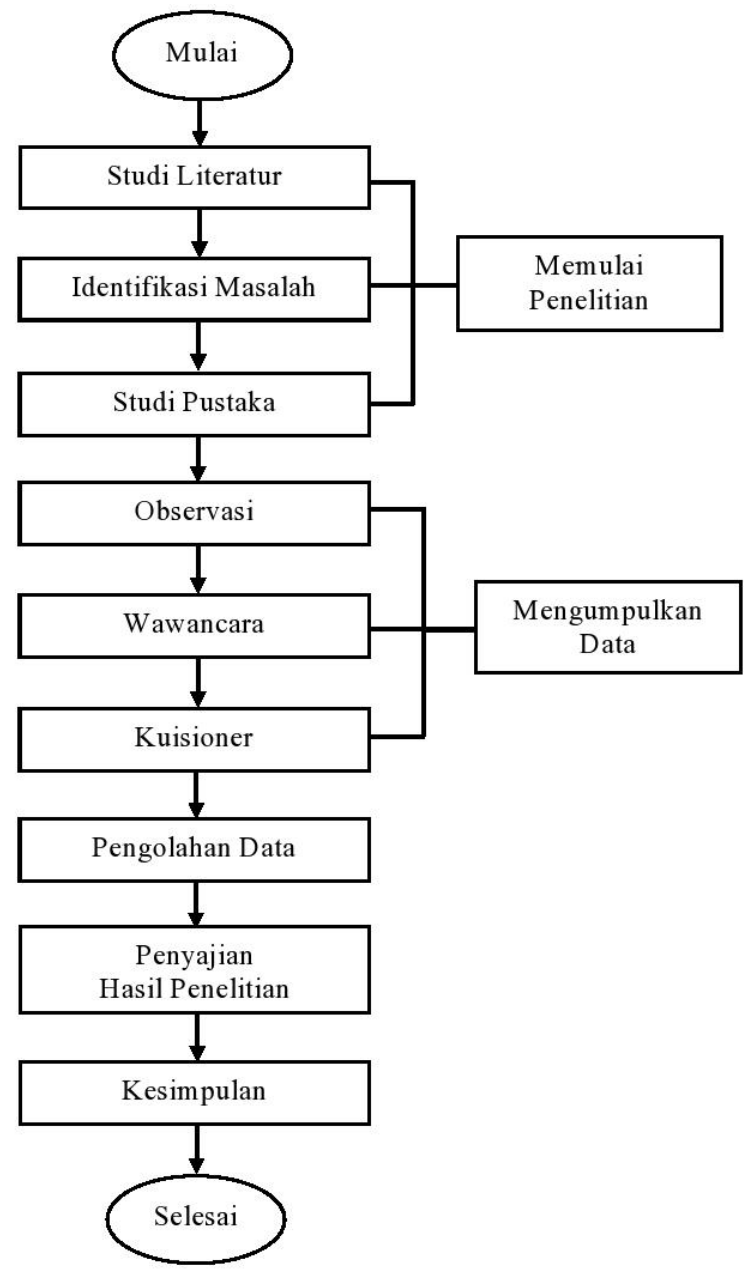

Gambar 1. Alur Kerja Metode Penelitian

Alur metode penelitian menggunakan tahapan seperti yang ada pada gambar, pertama yakni melakukan penelitian awal berupa studi literatur yang berkaitan dengan topik penelitian, kemudian dari hasil studi literatur selanjutnya mengidentifikasi masalah yang ada, setelah itu studi kasus pada tempat yang akan dijadikan sumber penelitian. Proses selanjutnya yang dilakukan yakni mengumpulkan data, pengumpulan data didapat dari melakukan observasi, mewawancarai karyawanataustaff yang bersangkutan, kemudian memberikan angket kuesioner kepada karyawan atau staff yang memakai aplikasi yang digunakan.

Untuk tahap pembagian kuesioner, penelitian ini menggunakan tabel RACI dapat dilihat pada tabel 2, tabel ini digunakan untuk mengidentifikasi proses serta fungsi pekerjaan yang diinginkan dalam menyelesaikan masalah. Secara sederhana RACI (Responsible, Accountable, Consulted, dan Informed) menerangkan siapa saja yang terlibat dalam suatu tindakan pada sebuah organisasi baik perusahaan maupun pemerintahan [9]. Setelah proses penelitian awal dan pengumpulan data maka dilakukan proses pengolahan data yang selanjutnya akan dijadikan suatu hasil akhir yaknipenyajian hasil penelitian kemudian dibuat berupa hasil kesimpulan terkait data dari tempat studi kasus serta penelitian yang sudah dilakukan. 
Tabel 2. RACI

\begin{tabular}{|c|l|l|}
\hline RACI & \multicolumn{1}{|c|}{ Fungsi atau Peran } & \multicolumn{1}{c|}{ Responden } \\
\hline Responsible & $\begin{array}{l}\text { Memastikan aktivitas tertentu } \\
\text { dapat dilaksanakan }\end{array}$ & Kepala UPPD Salatiga \\
\hline Accountable & $\begin{array}{l}\text { Berkewenangan memutuskan } \\
\text { untuk menerima atau } \\
\text { menyetujui pelaksanaan }\end{array}$ & $\begin{array}{l}\text { Kepala Sub Bagian Tata } \\
\text { Usaha UPPD Salatiga (Admin } \\
\text { Data) }\end{array}$ \\
\hline Consulted & $\begin{array}{l}\text { Pemberi pendapat atau yang } \\
\text { mendapatkannya dibutuhkan } \\
\text { dalam sebuah aktivitas }\end{array}$ & $\begin{array}{l}\text { Kepala Sub Bagian Tata } \\
\text { Usaha UPPD Salatiga (Admin } \\
\text { Data) }\end{array}$ \\
\hline \multirow{2}{*}{ Informed } & $\begin{array}{l}\text { Pihak yang diinformasikan } \\
\text { maupun mengkonsumsi hasil } \\
\text { pekerjaan }\end{array}$ & 11 Orang karyawan (User) \\
\hline
\end{tabular}

\section{HASIL DAN PEMBAHASAN}

Penggunaan hardware, jaringan, seta sistem pada UPPD Kota Salatiga sudah diatur oleh Kantor Pusat Jawa Tengah yakni kantor yang berada di Semaranag. Jadi semua sistem yang digunakan sudah terintegrasi dengan pusat, untuk maintenance dan service juga sudah merupakan wewenang dari pusat, karyawan atau staff IT di UPPD Kota Salatiga bertugas sebagai operator dan pengguna sistem yang sudah di sediakan

Pada bagian ini terdapat pembahasan mengenai hasil tingkat kematangan atau Maturity Level pada UPPD Kota Salatiga, dimana data diperoleh melalui hasil observasi, wawancara dan kuesioner. Pada kuesioner yang diberikan kepada Kepala UPPD Kota Salatiga, admin sistem, serta karyawan pengguna, digunakan standar kelayakan berdasarkan COBIT 4.1 dimana didalamnya peneliti menggunakan Domain ME (Monitoring and Evaluate) yang memiliki 4 kontrol ME1 (Monitor and Evaluate IT Performance), ME2 (Monitor and Evaluate Internal Control), ME3 (Obtain Independent Assurance), dan ME4 (Provide IT Governance).

Penelitian ini difokuskan untuk melihat proses manajemen, pengelolaan pengendalian internal serta berjalan atau tidaknya peraturan yang sudah dibuat. Semua proses yang mendukung jalannya proses bisnis serta visi dan misi instansi diperlukan adanya pengawasan dan evaluasi demi terjaganya kualitas sebuah instansi.

\subsection{ME1 Monitor and Evaluate}

Beberapa Temuan pada ME1 Monitor and Evaluate dari adalah :

- Masih diperlukan suatu adaptasi terhadap proses penggunaan teknologi informasi.

- Kurangnya monitor terhadap kerangka pemantauan yang telah dibentuk untuk mengukur solusi teknologi terhadap informasi bisnis

- Belum adanya prosedur untuk melacak akar penyebab kesalahan yang terjadi pada sistem.

- Belum adanya pemantauan umpan balik terhadap laporan tinjauan manajemen terkait sejauh mana tujuan yang direncanakan tercapai maupun target kinerja yang sudah terpenuhi.

- Masih kurangnya pemantauan terhadap proses pengumpulan data yang akurat dan tepat waktu demi kemajuan target yang sudah ditetapkan. 
Tabel 3. Hasil Kuesioner ME1 Monitor and Evaluate

\begin{tabular}{|c|c|c|}
\hline Domain & Keterangan & Rata-Rata Hasil \\
\hline ME1.1.1 & Monitoring Approach & 3,8 \\
\hline ME1.1.2 & Monitoring Approach & 3 \\
\hline ME1.2.3 & Definition and Collection or Monitoring Data & 4 \\
\hline ME1.3.1 & Monitoring Method & 3 \\
\hline ME1.4.1 & Performance Assessment & 4,5 \\
\hline ME1.5.1 & Board and Executive Reporting & 3 \\
\hline ME1.5.2 & Board and Executive Reporting & 4 \\
\hline ME1.5.3 & Board and Executive Reporting & 3 \\
\hline ME1.6.1 & Remedial Actions & 3,8 \\
\hline ME1.6.2 & Remedial Actions & 3,8 \\
\hline & Rata-Rata & $\mathbf{3 , 5 9}$ \\
\hline
\end{tabular}

Rekomendasi ME1 Monitor and Evaluate dari hasil penelitian adalah :

- Perlunya diadakan sosialisasi untuk adaptasi terhadap proses penggunaan teknologi agar karyawan dapat paham dan mengerti untuk penggunaan sistem aplikasi E-Presensi.

- Dibutuhkan adanya monitor terhadap kerangka pemantauan yang telah dibentuk supaya dapat menerapkan solusi bisnis terkait teknologi informasi.

- Diharapkan dibentuk suatu proses dalam sistem untuk melacak akar penyebab kesalahan yang terjadi pada E-presensi agar penggunaannya lebih optimal.

- Dilakukannya umpan balik terhadap laporan tinjauan manajemen yang terpantau agar tujuan bisnis dan target kinerja dapat terpenuhi dan terealisasi.

- Perlunya pemantauan proses pengumpulan data yang akurat dan tepat waktu secara berkala.

3.2 ME2 Monitor and Evaluate Internal Control

Beberapa Temuan pada ME2 Monitor and Evaluate Internal Control adalah :

- Masih kurangnya pemantauan untuk terhadap efisiensi dan efektivitas kontrol teknologi informasi untuk manajerial internal

- Belum dipantaunya pelaporan masalah kepada bagian yang bertanggung jawab secara kolektif.

- Diperlukan adanya analisis dan identifikasi yang mendalam terhadap akar penyebab kesalahan kontrol pada sistem.

- Perlunya pemantauan evaluasi kelengkapan dan efektivitas pengendalian manajemen atas proses teknologi informasi, kebijakan dan kontrak melalui program berkelanjutan dari selfassessment.

Tabel 4. Hasil Kuesioner ME2 Monitor and Evaluate Internal Control

\begin{tabular}{|c|c|c|}
\hline Domain & Keterangan & Rata-Rata Hasil \\
\hline ME2.1.1 & Monitoring of Internal Control Framework & 4,1 \\
\hline ME2.2.1 & Supervisory Review & 4 \\
\hline ME2.3.1 & Control Exceptions & 3,8 \\
\hline ME2.3.2 & Control Exceptions & 3,9 \\
\hline ME2.4.1 & Control Self-assessment & 3,5 \\
\hline \multicolumn{2}{|c|}{ Rata-Rata } & $\mathbf{3 , 8 6}$ \\
\hline
\end{tabular}


Rekomendasi ME2 Monitor and Evaluate Internal Control dari hasil penelitian adalah :

- Dilakukan pemantauan terhadap kontrol teknologi informasi berdasarkan efisiensi dan efektivitas untuk manajerial internal.

- Diharapkan laporan masalah kepada pihak yang bertanggung jawab secara kolektif dapat dipantau secara berkala.

- Melakukan Analisis dan Identifikasi kesalahan kontrol pada sistem supaya dapat ditemukan solusi dari akar penyebabnya.

- Dibentuknya kerangka pemantauan untuk mengevaluasi kelengkapan dan efektivitas pengendalian manajemen atas proses teknologi informasi, kebijakan dan kontrak berdasarkan program berkelanjutan dari self-assessment.

\subsection{ME3 Obtain Independent Assurance}

Beberapa Temuan pada ME1 Obtain Independent Assurance adalah:

- Masih kurangnya pemantauan terhadap kebijakan, peraturan, serta persyaratan eksternal dalam IT yang harus dipenuhi untuk proses kebijakan instansi.

- Kurangnya sosialisasi terhadap penyesuaian hukum, kontrak dan peraturan terhadap kebijakan teknologi informasi yang diterapkan pada instansi terkait.

- Perlunya pemantauan terhadap kepatuhan kebijakan teknologi informasi, standar, prosedur dan metodologi dengan persyaratan hukum dan peraturan berlaku.

Tabel 5. Hasil Kuesioner ME3 Obtain Independent Assurance

\begin{tabular}{|c|c|c|}
\hline Domain & Keterangan & $\begin{array}{c}\text { Rata-Rata } \\
\text { Hasil }\end{array}$ \\
\hline ME3.1.1 & $\begin{array}{c}\text { Identification of External Legal, Regulatory and Contractual } \\
\text { Compliance Requirements }\end{array}$ & 3,5 \\
\hline ME3.2.1 & Optimization of Response to External Requirements & 3,9 \\
\hline ME3.3.1 & Evaluation of Compliance With External Requirements & 4 \\
\hline ME3.4.1 & Positive Assurance of Compliance & 4 \\
\hline ME3.5.1 & Integrated Reporting & 3 \\
\hline \multicolumn{2}{|c|}{ Rata-Rata } & $\mathbf{3 , 6 8}$ \\
\hline
\end{tabular}

Rekomendasi ME3 Obtain Independent Assurance dari hasil penelitian adalah :

- Perlunya dibuat agenda Pemantauan secara berkala terhadap kebijakan, peraturan, serta persyaratan external dalam IT agar selaras dengan kebijakan instansi.

- Diadakannya sosialisasi terkait penyesuaian hukum, kontrak dan peraturan terhadap kebijakan teknologi informasi.

- Diharapkan pemantauan terhadap kebijakan, standar, prosedur, dan metodologi teknologi informasi dapat terealisasi secara teratur mengingat persyaratan dan peraturan hukum yang berlaku dapat berubah mengikuti kebijakan - kebijakan baru.

\subsection{ME4 Provide IT Governance}

Beberapa Temuan pada ME1 Provide IT Governance adalah:

- Masih kurangnya pengawasan penyelarasan kerangka tata kelola teknologi informasi dengan kepatuhan hukum terhadap peraturan, strategi dan tujuan instansi.

- Masih kurangnya pemahaman antara bisnis dan teknologi informasi sebagai salah satu strategi bisnis.

- Masih kurangnya penerapan aturan dan sistem kerja teknologi informasi untuk mendukung tujuan strategi bisnis instansi.

- Belum ada monitoring untuk pengelolaan aset teknologi informasi instansi. 
- Masih kurangnya monitoring terhadap alokasi dan penilaian sumber daya teknologi informasi sesuai dengan tujuan strategis institusi.

Tabel 6. Hasil Kuesioner ME4 Provide IT Governance

\begin{tabular}{|c|c|c|}
\hline Domain & Keterangan & Rata-Rata Hasil \\
\hline ME4.1.1 & Establishment of an IT Governance Framwork & 4,2 \\
\hline ME4.1.2 & Establishment of an IT Governance Framwork & 4 \\
\hline ME4.2.1 & Strategic Alignment & 3,5 \\
\hline ME4.2.2 & Strategic Alignment & 4 \\
\hline ME4.2.3 & Strategic Alignment & 4,2 \\
\hline ME4.2.4 & Strategic Alignment & 4,3 \\
\hline ME4.3.1 & Value Delivery & 3 \\
\hline ME4.3.2 & Value Delivery & 3,9 \\
\hline ME4.3.3 & Value Delivery & 4 \\
\hline ME4.4.1 & Resource Management & 4,1 \\
\hline \multicolumn{2}{|c|}{} \\
\hline
\end{tabular}

Rekomendasi ME4 Provide IT Governance dari hasil penelitian adalah :

- Perlunya pengawasan untuk penyelarasan kerangka tata kelola teknologi informasi dengan kepatuhan hukum terhadap peraturan, strategi dan tujuan instansi.

- Diharapkan karyawan benar-benar paham mengenai tujuan antara bisnis dan teknologi informasi sebagai salah satu tujuan bisnis instansi

- Dipantaunya penerapan penggunaan sistem yang baik terhadap aturan penggunaan sistem dari E-presensi demi mendukung tujuan strategi bisnis instansi

- Perlunya analisis dan monitoring pengelolaan dalam aset teknologi informasi instansi.

- Pengawasan berkala terhadap alokasi dan penilaian sumber daya teknologi informasi sesuai dengan tujuan strategi institusi.

\subsection{Hasil Perhitungan Maturity Level}

Menggunakan domain Monitor and evaluate pada COBIT 4.1 perkembangan tata kelola IT pada sistem absensi karyawan UPPD Kota Salatiga dapat diukur serta diidentifikasi tingkat kematangannya. Pada penelitian berikut, hasil diperoleh setelah melalui hasil observasi, wawancara, dan kuesioner pada karyawan terkait. Dibawah ini hasil perhitungannya :

Tabel 7. Hasil Perhitungan Maturity Level Domain ME

\begin{tabular}{|c|c|c|c|}
\hline $\begin{array}{c}\text { Sub } \\
\text { Domain }\end{array}$ & Keterangan & Nilai & Kondisi \\
\hline ME1 & Monitor and Evaluate IT Performance & 3,59 & Defined Process \\
\hline ME2 & Monitor and Evaluate Internal Control & 3,86 & Defined Process \\
\hline ME3 & Obtain Independent Assurance & 3,68 & Defined Process \\
\hline ME4 & Provide IT Governance & 3,92 & Defined Process \\
\hline \multicolumn{2}{r|}{ Rata - Rata } & $\mathbf{3 , 8}$ & Defined Process \\
\hline
\end{tabular}

Dapat dilihat pada hasil perhitungan tabel diatas bahwa rata - rata nilai Maturity Level yang diperoleh UPPD Kota Salatiga khususnya pada domain ME yaitu 3,8 dimana sudah ada di level Defined Process. 
Tabel 8. Hasil Rata - rata Maturity Level

\begin{tabular}{|c|c|c|c|}
\hline \multirow{2}{*}{ Domain } & \multicolumn{3}{|c|}{$\begin{array}{c}\text { Nilai Maturity Level Rata - Rata } \\
\text { Keseluruhan }\end{array}$} \\
\cline { 2 - 4 } & Saat Ini & Diharapkan & GAP \\
\hline ME & 3,8 & 4 & $4-3,8$ \\
\hline \multicolumn{3}{|c|}{ Rata - Rata } & $\mathbf{0 , 2 4}$ \\
\hline
\end{tabular}

Analisis Domain ME yang sudah dilakukan pada UPPD Kota Salatiga memiliki rata rata nilai maturity level sejumlah 3,8 yang sudah termasuk tingkat 3 yakni Defined Process. Maka dari itu level yang diharapkan adalah tingkat 4 yakni Managed and measurable. Diketahui kesenjangan atau GAP nilai rata - rata yang didapat dari pengurangan hasil expected level dengan current level yang didapat dari instansi yaitu 0,24.

\subsection{Hasil Analisis GAP Maturity Level}

Maturity level merupakan proses tata kelola teknologi informasi merupakan kondisi ideal tingkat kematangan proses yang diharapkan, yang akan menjadi acuan [3] dalam model tata kelola TI pada aplikasi absensi E-presensi di UPPD Kota Salatiga. Dari hasil penelitian yang dilakukan melalui observasi, tinjauan pustaka, wawancara, hasil kuesioner serta melihat lingkungan internal, tujuan serta visi dan misi UPPD Kota Salatiga maka didapatkan hasil maturity level pada ME1, ME2, ME3, ME4 berada pada tingkat 3 (Defined Proces), dapat dilihat gambar 2.

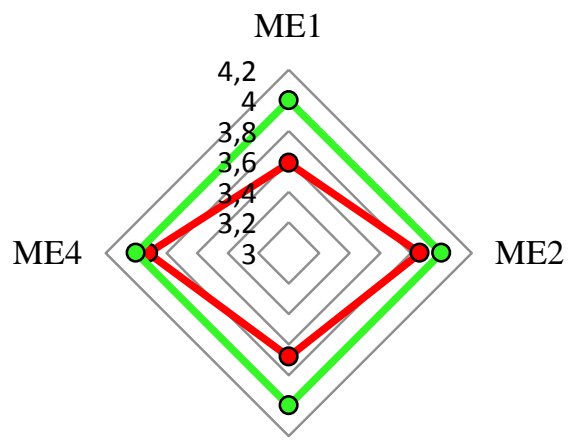

ME2

ME3

Gambar 2. Spider Chart Hasil Current dan Expected Maturity Level

Setelah mengetahui current dan expected levelnya, maka dicari nilai kesenjangan atau GAP yang diperoleh dengan cara melakukan pengurangan antara nilai expected level dengan current level mengidentifikasi jarak yang harus dilalui untuk mencapai level yang diharapkan [3]. Berikut ini adalah hasil dari penelitian maturity level dan GAP:

Tabel 6. Hasil Maturity Level

\begin{tabular}{|c|c|c|c|}
\hline \multirow{2}{*}{ Domain } & \multicolumn{3}{|c|}{ Nilai Maturity Level } \\
\cline { 2 - 4 } & Saat Ini & Diharapkan & GAP \\
\hline ME1 & 3,59 & 4 & 0,41 \\
\hline ME2 & 3,86 & 4 & 0,14 \\
\hline ME3 & 3,68 & 4 & 0,32 \\
\hline ME4 & 3,92 & 4 & 0,08 \\
\hline \multicolumn{3}{|c|}{ Rata - Rata } \\
\hline
\end{tabular}




\section{KESIMPULAN}

Pada penelitian yang sudah dilakukan dengan analisis dan kuesioner menggunakan COBIT 4.1 pada Instansi UPPD Kota Salatiga untuk mengukur tingkat kematangan, serta menilai kesesuaian sistem dengan tujuan bisnis instansi menggunakan Domain ME (Monitoring and Evaluate), dimana dalam domain ME terdapat beberapa subdomain, maka didapatlah hasil sebagai berikut:

- Institusi UPPD Kota Salatiga sudah mengimplementasi framework monitor and evaluate pada tingkat Defined Process, dari hasil data yang dikelola melalui hasil wawancara dan kuesioner yang diberikan pada karyawan, diketahui bahwa maturity level memiliki rata-rata 3,8 dengan expected level pada tingkat 4 yaitu managed and measurable, serta memiliki nilai GAP sebesar 0,2 .

- Melalui perhitungan hasil maturity level, dapat dilihat bahwa subdomain dengan nilai tertinggi berada pada ME4 yakni 3,92 yang berada pada level Defined Process dan untuk sudomain dengan nilai terendah berada pada ME1 dengan nilai 3,59 yang berada pada level Defined Process.

\section{SARAN}

Adapun saran yang dapat diberikan oleh penulis berdasarkan kesimpulan penelitian adalah sebagai berikut:

1. Instansi diharapkan dapat lebih memonitor jalannya proses pengumpulan data demi tinjauan proses yang lebih baik secara berkala.

2. dilakukannya proses sosialisasi bukan hanya terkait penggunaan tetapi juga untuk solusi penanganan masalah terhadap penggunaan - penggunaan aplikasi untuk pendukung kerja karyawan

3. Jumlah sampel untuk penelitian melalui kuesioner dan wawancara sebanyak 11 responden, jumlah yang masih relatif sedikit. Diharapkan peneliti selanjutnya menambahkan jumlah responden dan melakukan wawancara setiap bidang yang terkait untuk hasil penelitian yang lebih lengkap.

\section{UCAPAN TERIMA KASIH}

Terima kasih kepada tuhan yang maha esa, atas berkat rahmat serta penyertaanya, sehingga penulis bisa menyelesaikan Jurnal ini hingga selesai. Terima kasih juga kepada Keluarga, Bangtan Sonyeondan, dan Teman-teman terdekat karena sudah memberikan semangat saat pengerjaan jurnal.

\section{DAFTAR PUSTAKA}

[1] Imami, Liliandara Wahyu, dkk. 2018, "Audit Tata Kelola Teknologi Informasi pada Dinas Komunikasi dan Informatika (DISKOMINFO) Kota Probolinggo Menggunakan Kerangka Kerja COBIT 4.1 Domain Plan and Organise dan Acquire and Implement", Jurnal Pengembangan Teknologi Informasi dan Ilmu Komputer, No. 8, Vol 2, hlm 34253432. 
[2] Affandi, Luqman, dkk . 2020. "Sistem Presensi Menggunakan NFC Smartphone Android dan Raspberry PI (Studi Kasus Politeknik Negeri Malang)”, JIP (Jurnal Informatika Polinema), No. 3, Vol 6, hlm 75-82.

[3] Gunawan, Catherine Kurniadi, dkk. 2018. "Audit Fingerprint pada PT X Dengan Framework COBIT 4.1” Jurnal Informatika dan Sistem Informasi, Vol 4, hlm 34-43.

[4] Rustam, B.R. 2017, Manajemen Risiko: Prinsip, Penerapan, dan Penelitian, Salemba Empat, Jakarta.

[5] Mardila, Muhhammad Bilal Mardila and Anna Mukhayaroh. 2020, "Audit Absensi Online Aplikasi BeeAtt Dengan Metode Cobit 4.1 Domain ME (Monitor and Evaluate) pada PT. Prawathiya Karsa Pradiptha Bekasi”, Bianglala Informatika, No. 2, Vol 8, hlm. 70-78.

[6] Ulfa, Dindha Maria, Suprapto, Yusi Tyroni Mursityo. 2019, "Evaluasi Tata Kelola Teknologi Informasi Dinas Komunikasi dan Informatika Kota Batu Menggunakan Kerangka Kerja COBIT 4.1 Dengan Domain Deliver and Support (DS) dan Monitor and Evaluate (ME)", Jurnal Pengembangan Teknologi Informasi dan Ilmu Komputer, No. 4, Vol 3, hlm 2148-3156.

[7] Taqiya, Namira Abda, Siti Mukaromah, and Arista Pratama. 2020, "Analisis Tingkat Kematangan SPBE di Dinas Komunikasi dan Informatika Jawa Timur”, SCAN - Jurnal Teknologi Informasi dan Komunikasi, No. 1, Vol 15, hlm 22-33.

[8] Yunus, Indrei Rahmawati, Nadiyasari Agitha, Sri Endang Anjarwani. 2019, "Analisis Tata Kelola Teknologi Informasi pada Layanan Infrastruktur Jaringan RSUD Provinsi NTB Menggunakan COBIT 4.1", JTIKA, No. 1, Vol 1, hlm 19-30.

[9] Rumere, Harold Michael, dkk. 2020, "Analisis Kinerja Tata Kelola Teknologi Informasi pada Dinas Perpustakaan dan Kearsipan Daerah Kota Salatiga Menggunakan Framework COBIT 5.0”, SEBATIK, No. 2, Vol. 24, hlm 14-21.

[10] Rachmatsya, Agus Dendi. 2018, "Pengembangan Aplikasi Aok-Jek Menggunakan Kerangka Kerja COBIT 4.1 Untuk Meningkatkan Pelayanan Pelanggan", JATISI, No. 1, Vol 5, hlm 24-35.

[11] Zenius "Pengetian Penelitian Kuantitatif", https://www.zenius.net/prologmateri/sosiologi/a/801/penelitiankuantitatif, Diakses tgl 16 Februari 2021.

[12] Oky Sugianto "Penelitian Kualitatif, Manfaat dan Alasan Penggunaan", https://binus.ac.id/bandung/2020/04/penelitian-kualitatif-manfaat-dan-alasanpenggunaan/, Diakses tgl 16 Februari 2021.

[13] Guru Pendidikan "Metode Penelitian Gabungan", https://www.gurupendidikan.co.id/metode-penelitian-gabungan/, diakses tgl 16 Februari 2021 